\title{
COVID-19 E A EMINENTE CRISE ECONÔMICA: COMO A GESTÃO PÚBLICA MUNICIPAL BRASILEIRA PODE CONTRIBUIR?
}

\author{
MIRANDA, Marconi Silva ${ }^{1}$ \\ MENDES, Wesley de Almeida ${ }^{2}$ \\ MACEDO, Suélem Viana ${ }^{3}$ \\ MENDES, Wanderson de Almeida ${ }^{4}$ \\ REIS, Anderson de Oliveira
}

\begin{abstract}
Recebido em: 2021.01 .04
Aprovado em: 2021.04.14

ISSUE DOI: $10.3738 / 1982.2278 .3887$

RESUMO: Para investigar a gestão pública municipal, este artigo teve como objetivo analisar o comportamento das receitas próprias e despesas correntes dos municípios brasileiros entre os anos de 2006 e 2016. Parte-se do pressuposto que a contenção dos gastos e a maior responsabilidade na gestão pública municipal são caminhos para a otimização dos recursos públicos, possibilitando a sua utilização na saúde, principalmente, no nível primário. Tais medidas, por conseguinte, permitiriam os municípios aumentarem seus recursos próprios para prevenir e diagnosticar o COVID-19. A estratégia empírica consistiu no uso de estatística descritiva por meio de medidas de posição. Os resultados sugerem que, nos últimos anos, as despesas municipais aumentaram, principalmente os gastos com pessoal. Esse comportamento, caso se mantenha, pode comprometer a capacidade dos municípios em prover a saúde primária, agravando ainda mais os efeitos da pandemia. Frente à essa problemática, questiona-se a capacidade da gestão pública em administrar os recursos financeiros diante do grave quadro econômico que se anuncia devido à crise do COVID-19.
\end{abstract}

Palavras-chave: Receitas. Despesas. Saúde primária.

\section{COVID-19 AND THE IMMINENT ECONOMIC CRISIS: HOW CAN BRAZILIAN MUNICIPAL PUBLIC MANAGEMENT CONTRIBUTE?}

\begin{abstract}
SUMMARY: To investigate municipal public management, this article aimed to analyze the behavior of own revenues and current expenses of Brazilian municipalities between the years 2006 and 2016. It is assumed that the containment of expenses and greater responsibility in management municipal public services are ways to optimize public resources, enabling their use in health, especially at the primary level. Such measures, therefore, would allow municipalities to increase their own resources to prevent and diagnose COVID-19. The empirical strategy consisted of using descriptive statistics by means of position measures. The results obtained, in the last years, the municipal expenses increased, mainly the expenses with personnel. This behavior, if maintained, may compromise the ability of municipalities to prove primary health, further aggravating the effects of the pandemic. Faced with this problem, the capacity of public management to manage financial resources is questioned in view of the economic situation that is being announced due to the COVID-19 crisis.
\end{abstract}

Keywords: Revenue. Expenses. Primary health.

\footnotetext{
${ }^{1}$ ORCID ID - ORCID: http://orcid.org/0000-0001-8870-347X. Doutorando em Administração - PPG-ADM/UFV Universidade Federal de Viçosa (UFV).

${ }^{2}$ ORCID ID - http://orcid.org/0000-0001-6443-2572. Doutor em Administração - PPG-ADM/UFV. Universidade

Federal de Viçosa (UFV)

${ }^{3}$ ORCID ID - https://orcid.org/0000-0002-1610-1856. Doutoranda em Administração - PPG-ADM/UFV

Universidade Federal de Viçosa (UFV)

${ }^{4}$ ORCID ID- http://orcid.org/0000-0002-5667-2346 . Doutorando em Administração - PPG-ADM/UFV

Universidade Federal de Viçosa (UFV)

${ }^{5}$ ORCID ID- http://orcid.org/0000-0003-2861-5472. Doutor em Administração - PPG-ADM/UFV

Universidade Federal de Viçosa (UFV)
}

Nucleus, v.18, n.1, abr.2021 


\section{INTRODUÇÃO}

A crise mundial causada pelo COVID-19 que vem atingindo o sistema de saúde e a economia de quase todos os países, também chegou ao Brasil. Porém, as ações dos entes federados em relação a esse grave problema não convergem para um lugar comum. De um lado o governo federal adota a postura de minimizar os efeitos do isolamento, contrariando medidas do próprio ministério da saúde e da Organização Mundial da Saúde (OMS), sob a narrativa de se atenuar os efeitos de uma eminente crise econômica. Já os governos subnacionais, seguindo orientações internacionais e considerando o elevado número de óbitos ocorridos no país, adotam medidas mais restritivas de isolamento, com o discurso de preservar a vida e ganhar tempo para estruturar melhor os seus sistemas de saúde.

Nessa "queda de braço" insere-se o desenho do federalismo brasileiro previsto na Constituição Federal de 1988 (CF/88), que divide os poderes políticos e atribui a cada nível de governo a sua própria autonomia, indo muito além de uma simples divisão de tarefas administrativas (MENDES, 2004). Já o federalismo fiscal, com base na Teoria da Descentralização Fiscal, atribui competências fiscais a União, estados e municípios (MUSGRAVE; MUSGRAVE, 1989).

No entanto, apesar da autonomia, vários estudos empíricos mostram que os municípios brasileiros, em sua maioria, dependem fundamentalmente dos recursos da União, devido à baixa estrutura econômica que possuem (MARENCO; STROHSCHOEN; JONER, 2017; MASSARDI; ABRANTES, 2014; MENDES et al., 2018; SILVA; QUINTELA; VIEIRA, 2018; VIEIRA et al., 2017). Essa dependência tem influenciado a capacidade desses municípios em servir a população e promover o desenvolvimento econômico (LEROY et al., 2017; SUZART; ZUCCOLOTTO; ROCHA, 2018).

Todavia, o país se encontra em um quadro de recessão econômica, o Produto Interno Bruto (PIB), por exemplo, não tem um crescimento relevante desde 2014 (DE HOLANDA BARBOSA FILHO, 2017). Ademais, em 2017 a economia teve pouco crescimento, com previsão pouco otimista pelo menos até 2019, com taxas de crescimento baixa e volátil (MENDONÇA; JORGE, 2019; SICSU, 2019).

Não obstante, a crise que se anuncia, devido ao COVID-19, pode agravar ainda mais a condição econômica do país a médio e longo prazo. Entretanto, apesar da posição de dependência econômica dos municípios brasileiros e o quadro de adversidade financeira que já vem de algum tempo, estudos evidenciam que, além das receitas vinculadas provenientes das transferências da União, os municípios brasileiros têm aumentado os gastos dos recursos próprios com saúde 
(ARAÚJO; GONÇALVES; MACHADO, 2017; DO ESPÍRITO SANTO; TANAKA, 2011; LEITE; LIMA; DE VASCONCELOS, 2012; VARELA; FARINA, 2007).

Soma-se a tudo isso, ainda, a pandemia do COVID-19, que impõe uma situação ímpar, talvez jamais vivida pela administração pública brasileira. Nessa conjuntura encontram-se, também, os gestores dos municípios brasileiros, que há algum tempo já convivem com muitas dificuldades econômicas.

Assim, dado o quadro econômico que se vislumbra devido a COVID-19, levanta-se a seguinte questão: o comportamento das finanças públicas dos municípios brasileiros nos últimos anos dá algum indício que as futuras decisões podem ser no sentido de conter os gastos públicos? Diante disso, o objetivo geral desse estudo é analisar o comportamento das receitas próprias, bem como das despesas correntes e com pessoal dos municípios brasileiros nos últimos anos.

Esse estudo parte do pressuposto que a contenção dos gastos e a maior responsabilidade na gestão municipal são caminhos para a otimização dos recursos públicos, a fim de que os mesmos possam ser utilizados para melhor atendimento à população em todas as áreas, inclusive na saúde, principalmente, no nível primário. Tais medidas possibilitariam os municípios aumentarem, por exemplo, seus recursos próprios na prevenção e diagnóstico da COVID-19.

\section{TEORIA DA DESCENTRALIZAÇÃO, FEDERALISMO E FEDERALISMO FISCAL BRASILEIRO}

Em um governo federalista, descentralização fiscal é a participação dos entes subnacionais no financiamento e nos gastos governamentais (MUSGRAVE; MUSGRAVE, 1989). Desta forma a descentralização fiscal aborda: autonomia, funções fiscais, competências tributarias, transferências fiscais e a relevância da ação coordenadora liderada pelo governo central (SILVA, 2005).

Alguns questionamentos em relação à descentralização fiscal têm provocados debates entre os estudiosos dessa teoria. Bahl e Linn (2016), descrevem que descentralização fiscal melhora a eficiência alocativa do setor público, e reprime a intervenção estatal na economia. Além disso, a descentralização fiscal provoca concorrência no provimento de serviço público local, o que tem efeito positivo na gestão pública (BRENNAN; BUCHANAN, 1980).

Entretanto, alguns autores apontam falhas na descentralização fiscal. Prud'homme (1995), descreve que esse modelo fiscal aumenta a disparidade regional, dificulta o controle macroeconômico, gera gastos públicos desnecessários e aumenta a corrupção.

Musgrave (1959), ao analisar o imposto sobre propriedade dos Estados Unidos, principalmente sobre terrenos e imóveis aponta fatores negativos da descentralização fiscal. “As ineficiências resultantes são um custo da descentralização fiscal que pode ser eliminado apenas 
pela equalização de taxas efetivas, pelo menos nas jurisdições vizinhas, como unidades dentro de uma área metropolitana" (MUSGRAVE, 1959, p. 417).

No cerne da discussão sobre descentralização fiscal está o Federalismo e sua diversidade no grau de descentralização. Apesar de não haver consenso na literatura sobre a definição de federalismo, a maioria dos autores o define como a forma de Estado, em que de maneira autônoma e simultânea, coexistem diferentes níveis de poder, cada um atuando de forma independente sobre a sociedade (SOUZA, 2005). No mesmo sentido, federalismo é a divisão de poderes políticos e constitucionais entre os diferentes níveis de governo, indo muito além de uma simples divisão de tarefas administrativas (MENDES, 2004).

Todavia, na década de 80, a partir do governo Reagan nos Estados Unidos, surgiram conceitos de um novo federalismo. A filosofia do novo federalismo, foi enfatizar a descentralização, incluindo maior dependência de gastos estaduais e locais, bem como maior discrição no uso de doações federais por parte dos beneficiários (MUSGRAVE; MUSGRAVE, 1989).

O federalismo em termos organizacionais tem o setor público como o condutor das decisões, intermediando as operações do governo central e subnacionais. Porém, para distribuir as competências constitucionais fiscais entre esses diferentes níveis de governo, adota-se o federalismo fiscal (SILVA, 2005).

Neste sentido, federalismo fiscal consiste na divisão de tarefas fiscais, entre os diferentes níveis de governo, de quem deve arrecadar cada um dos tributos do país e de quem deve ofertar cada um dos serviços públicos (MENDES, 2004). Entretanto, cada país tem que determinar qual é melhor forma de equalizar a autonomia tributária dos seus governos subnacionais (BIRD; TARASOV, 2004).

O federalismo fiscal pode ser dividido basicamente em duas gerações. A primeira geração (OATES, 2003), mais tradicional, define a descentralização fiscal como seu principal objeto. A segunda (WEINGAST, 2009), procura redefinir o conceito de descentralização, sob a influência da Escolha Pública e da Nova economia Institucional.

Suzart, Zuccolotto e Rocha (2018), destacam que o foco da primeira geração está nas atribuições dos diferentes níveis governamentais. Ressalta-se, que a teoria tradicional do federalismo fiscal estabelece uma estrutura normativa geral para a atribuição de funções a diferentes níveis de governo e os instrumentos fiscais apropriados para a realização dessas funções (OATES, 1999). "Um dos papéis do governo central seria o de indicar as situações nas quais a produção local de bens públicos resulta em extravasamentos para outras comunidades, compensando-as com subsídios unitários” (VARGAS, 2011, p. 54). 
A segunda geração por sua vez, buscou se distanciar da visão Keynesiana de Estado abordada por Musgrave e Oates, que atribuía uma importância maior ao governo central. Weingast (2009) destacou a importância de detalhar como o sistema fiscal funciona, a fim de ter uma base firme para entender as consequências que suas mudanças podem acarretar.

Essa nova teorização assentou-se, em especial, na Escolha Pública, cujo campo de análise se deu predominantemente sobre a esfera política (SUZART; ZUCCOLOTTO; ROCHA, 2018). Para Oates (2003), a segunda geração do federalismo fiscal, com o foco direcionado em maximizar suas utilidades, examinou o funcionamento de diferentes instituições fiscais em um cenário de imperfeição.

$\mathrm{Na}$ literatura internacional, em um estudo sobre as diferenças fiscais entre Estados Unidos e Alemanha, (FUNASHIMA; HIRAGA, 2017) com objetivo de entender como o sistema funciona, com base na teoria clássica do federalismo fiscal, apresentaram resultados que mostram que as caraterísticas da disciplina fiscal são os principais determinantes para o crescimento do tamanho do governo.

Já Rodden (2002), abordou os desafios das indisciplinas fiscais entre os governos subnacionais, tanto em países desenvolvidos como em desenvolvimento. Suas conclusões destacam que os governos centrais, constrangidos constitucionalmente ou politicamente, assumem pesadas obrigações de cofinanciamento, geralmente não podem se comprometer de maneira credível a ignorar os problemas fiscais dos governos de nível inferior (RODDEN, 2002).

Akin, Bulut-Cevik e Neyapti (2016), buscam identificar se a descentralização fiscal promove disciplina fiscal. Segundo os autores, o federalismo fiscal tem efeito disciplinar fiscal quando a restrição orçamentária é vinculada, mas quando o governo local não sofre restrição orçamentária, o governo central é mais eficiente.

No Brasil, o federalismo, diferente de alguns países, é formado por três níveis: União, estados e municípios. A cada um desses níveis são atribuídas funções organizacionais, legislativas, governamentais e administrativas. A União se organiza por meio de sua Constituição Federal, os Estados pelas suas Constituições Estaduais, mesmo que quase todas sejam mera repetição da constituição federal, e os municípios pelas suas leis orgânicas (SOUZA, 2005). A Constituição Federal brasileira $(\mathrm{CF} / 88)$, assegura a capacidade tributária aos três níveis de governo, sendo que alguns tributos são exclusivos da esfera que os arrecada, outros são coletados pela União e distribuídos com estados e municípios e outros são arrecadados pelos estados e partilhados com os municípios (ARRETCHE, 2005; SOUZA, 2005).

Ainda segundo Souza (2005), o federalismo brasileiro tem apresentado característica centralizadora. A autora descreve que o nosso federalismo tem sido marcado por políticas públicas federais que se impõem às instâncias subnacionais, em detrimento a poucas 
competências constitucionais alocadas a estados e municípios. No entanto, o federalismo brasileiro também é descentralizador, uma vez que estados e municípios possuem uma considerável autonomia administrativa. No que se refere às competências, do ponto de vista constitucional, todos os níveis da federação possuem poderes e competência iguais.

Para Arretche (2005), a opção por três níveis da federação, pela responsabilidade compartilhada dos principais serviços públicos, em especial os sociais, provocam conflitos sobre qual nível é responsável por qual política ou serviço público. Porém Souza (2005), afirma que o poder favorece a União devido ao seu papel central na definição das políticas públicas, por outro lado, alguns afirmam que essa divisão de poder favorece o governo local, que vem expandindo sua autonomia ao longo da história.

O federalismo fiscal brasileiro, surge timidamente nos anos 30, com uma fragmentação de recursos financeiros por parte União com os outros níveis de governo. A partir das assembleias nacionais constituintes de 1934, os grandes embates disseram respeito sobre o sistema de transferências fiscais (ARRETCHE, 2005). Mais tarde durante a ditadura militar, apesar de um aumento na centralização da arrecadação fiscal em relação a União, a reforma tributária de 1967 instala o sistema de transferências governamentais.

Passado o período militar, a Constituição Federal de 1988 foi a responsável por estabelecer definitivamente as bases do federalismo fiscal nacional. Um dos objetivos da descentralização fiscal no Brasil foi o fortalecimento financeiro e político de Estados e municípios em detrimento do governo central como forma de fortalecer a democracia então em vias de restabelecimento (GUEDES; GASPARINI, 2007).

A Constituição de 1988 no seu ímpeto descentralizador elevou os municípios ao status constitucional de quase membro da federação brasileira e, ao mesmo tempo facilitou sua criação - de pouco mais de 4 mil para 5 mil unidades (SERRA; AFONSO, 1999).

Rezende (2006) ressalta, porém, que uma das críticas mais comuns à Constituição de 1988 em relação ao federalismo fiscal no Brasil foi que ela promoveu uma forte descentralização de recursos, mas não de atribuições. Outra crítica ao federalismo fiscal brasileiro, foi o aumento das transferências das receitas tributárias originadas nos grandes municípios para os pequenos sem estimular a atividade produtiva nos municípios menores (MACDOWELL; GOMES, 2000).

Massardi e Abrantes (2015), apontam como uma das consequências do federalismo fiscal brasileiro, o baixo índice de esforço fiscal dos municípios pequenos e pouco industrializados, devido às altas taxas de transferenciais intergovernamentais. Ademais, os municípios brasileiros assumiram um maior nível de responsabilidade diante a sociedade. Pois, à 
luz do federalismo fiscal brasileiro, deve-se entender, que há despesas que estarão exclusivamente às expensas dos cofres municipais (SUZART; ZUCCOLOTTO; ROCHA, 2018).

Neste contexto, o da autonomia dada aos entes subnacionais, devido a descentralização fiscal por meio do federalismo fiscal brasileiro, insere-se a discussão deste estudo. Afinal, no âmbito do pacto federativo nacional, uma gestão pública eficiente e responsável, pode contribuir para minimizar as desigualdades regionais em todas as esferas sociais, inclusive na atenção primária à saúde. Setor importante na prestação de serviços público, ainda mais diante do quadro de pandemia em que o país atravessa, devido os efeitos do COVID-19.

\section{METODOLOGIA}

A unidade de análise deste estudo compreendeu os 5.570 municípios brasileiros. Os dados foram seccionados em 11 pontos do tempo, entre os anos de 2006 a 2016. A delimitação do período foi feita de modo a captar o comportamento das receitas próprias e das despesas dos municípios brasileiros nos últimos anos, considerando a disponibilidade de dados no site Finanças Brasil (FINBRA), da Secretaria do Tesouro Nacional.

Para analisar as receitas próprias dos municípios utilizou-se as variáveis referentes ao Imposto Predial e Territorial Urbano (IPTU), Imposto Sobre a Transmissão de Bens e Imóveis (ITBI) e Imposto Sobre Serviços de Qualquer Natureza (ISSQN). Como estes impostos são de competência municipal, representam os instrumentos fiscais apropriados para a atribuição das funções fiscais deste nível de governo (OATES, 1999).

Já a variável transferências intergovernamentais, é um elemento fundamental no desenho do federalismo brasileiro. Pois, é por meio das transferências intergovernamentais que os tributos arrecadado pela União são partilhados com os municípios (ARRETCHE, 2005; SOUZA, 2005).

As variáveis utilizadas no estudo estão apresentadas no Quadro 1. Todos os valores monetários foram ajustados pelo Índice Geral de Preços (IGP-DI) da Fundação Getúlio Vargas FGV, na data de 31/12/2016, em milhares de reais e ponderadas pela população (per capita).

Para a execução dos objetivos usou-se estatística descritiva, por meio de medidas de posição (média aritmética). A estatística descritiva, segundo (SANTOS, 2018), é o conjunto de procedimentos e técnicas que servem para recolher, organizar, sintetizar e descrever os dados.

Quadro 1- Variáveis utilizadas na pesquisa

(Continua)

\begin{tabular}{|c|c|c|}
\hline Variáveis & Descrição & \multirow{2}{*}{ Fonte* } \\
\hline IPTU & Imposto Predial e Territorial Urbano & \multirow{2}{*}{ FINBRA } \\
\hline ITBI & Imposto Sobre a Transmissão de Bens e Imóveis & \\
\hline ISSQN & Imposto Sobre Serviços de Qualquer Natureza & \\
\hline Receita própria & Soma das receitas do IPTU ITBI, ISSQN & \\
\hline
\end{tabular}




\begin{tabular}{|c|c|c|}
\hline Variáveis & Descrição & Fonte* \\
\hline $\begin{array}{c}\text { Transferências } \\
\text { Intergovernamentais }\end{array}$ & Soma das receitas referentes a cota parte do FPM, ICMS e IPI & \\
\cline { 1 - 2 } Despesas correntes & Soma de todas as despesas correntes dos municípios brasileiros & \\
\cline { 1 - 2 } Despesas com pessoal & Despesa referente ao gasto com pessoal & \\
\hline
\end{tabular}

Fonte: Elaborado pelos autores.

*Dados secundários

Os municípios foram divididos em três grupos: o primeiro com até 49.999 habitantes, o segundo com a população de 50.000 a 99.999 habitantes e terceiro foi formado pelos municípios de 100.000 habitantes para cima. Tal divisão se justifica, pois os municípios menores, estão em regiões mais pobres, são economicamente mais vulneráveis e dependem consideravelmente das transferências intergovernamentais (MASSARDI; ABRANTES, 2014).

Finalmente, com o objetivo de obter um conjunto de dados mais robusto, os oultiers e os valores perdidos foram substituídos por meio da técnica de tratamento de dados denominada Winsorizing. Esta técnica faz a substituição de variáveis extremas por valores de determinado percentil escolhido pelo pesquisador (ERIKSSON et al., 2006).

\section{APRESENTAÇÃO E DISCUSSÃO DOS RESULTADOS}

As curvas traçadas na Figura 1 esboçam o comportamento das receitas próprias e das transferências intergovernamentais dos municípios brasileiros, entre os anos de 2006 e 2016. Os resultados indicam que durante o referido período as transferências intergovernamentais tiveram um crescimento percentual menor em relação ao aumento das receitas próprias dos municípios brasileiros. O que pode indicar um maior esforço fiscal por parte dos municípios diante da queda das transferências constitucionalmente garantidas. Enquanto nas receitas próprias o aumento per capita deflacionado passou de $\mathrm{R} \$ 90,91$, em 2006, para $\mathrm{R} \$ 154,86$, em 2016, aproximadamente $70,0 \%$, as transferências foram de $\mathrm{R} \$ 1.349,98$ para $\mathrm{R} \$ 1.811,74$, no mesmo período, o que representa crescimento em torno de $34,0 \%$.

Esses percentuais além apontar para um maior esforço fiscal por parte dos municípios brasileiros, pode servir como um alento no que se refere ao comportamento da gestão pública em um momento que tudo indica que as despesas públicas com saúde em todos os níveis, inclusive o primário, demandarão maiores recursos financeiros no combate a pandemia do COVID-19. 
Figura 1 - Comportamento geral das receitas próprias e das transferências intergovernamentais de todos os municípios brasileiros no período de 2006 a 2016

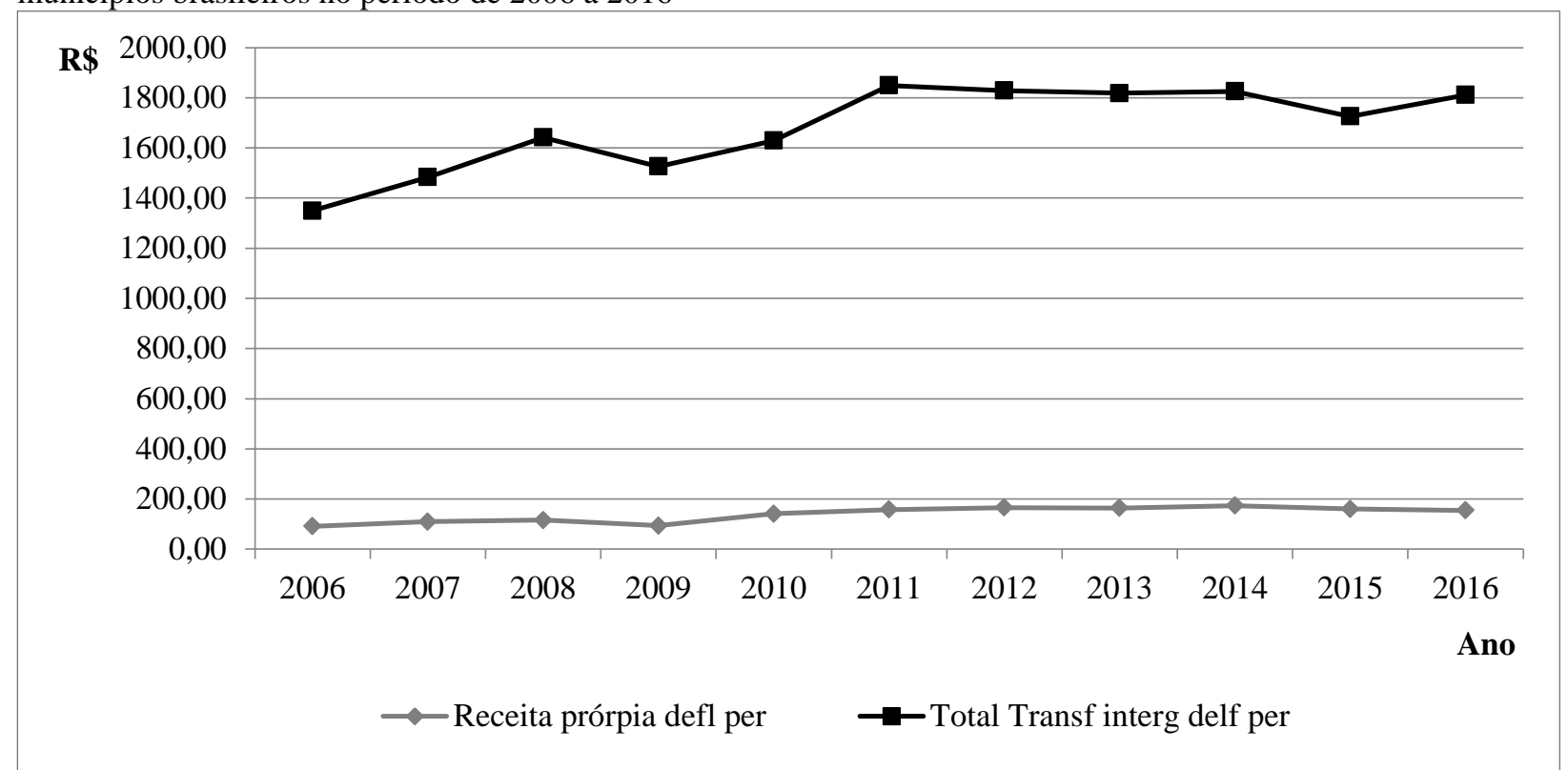

Fonte: Elaborado pelos autores com base nos resultados da pesquisa.

$\mathrm{Na}$ Tabela 1, é possível observar as receitas próprias e as transferências intergovernamentais ponderadas pela população. Em relação as receitas, elas são diretamente proporcionais ao tamanho do município, ou seja, os municípios maiores têm maior capacidade fiscal. Isso se deve, em parte, por terem maior estrutura econômica. Enquanto nos municípios com população até 49.999 habitantes a receita per capita é de $\mathrm{R} \$ 117,80$, nos municípios com mais de 100.000 habitantes, esses números chegam a aproximadamente $\mathrm{R} \$ 722,00$ per capita.

Tabela 1 - Eficiência da receita própria dos municípios brasileiros

\begin{tabular}{lccc}
\hline \multicolumn{1}{c}{ População } & Receita Própria* & $\begin{array}{c}\text { Transferências } \\
\text { Intergovernamentais }\end{array}$ & $\begin{array}{c}\text { Eficiência } \\
\text { Arrecadatória }^{* *}\end{array}$ \\
\hline Até 49.999 & 117,80 & 1899,32 & 6,20 \\
50.000 a 99.999 & 289,68 & 1033,14 & 28,04 \\
100.000 para cima & 721,79 & 891,39 & 80,97 \\
\hline
\end{tabular}

Nota: ${ }^{*}$ Média em reais; ${ }^{* *}$ Valores percentuais.

Fonte: Elaborado pelos autores com base nos resultados da pesquisa.

Esse resultado está em conformidade com os achados de (MARENCO; STROHSCHOEN; JONER, 2017; MASSARDI; ABRANTES, 2016; MENDES et al., 2018; VIEIRA et al., 2017), que descrevem a existência de uma relação estreita entre a capacidade arrecadatória dos municípios e seu tamanho.

Resultados, que como descrito por (MUSGRAVE, 1959), podem indicar alguns dos fatores negativos da Teoria da Descentralização Fiscal. Além do mais, evidência a importância dos instrumentos fiscais apropriados para os diferentes níveis de governo e o seu tamanho (OATES, 1999). 
Já a variável relativa às transferências intergovernamentais - compostas pelas cotas do FPM, ICMS e IPI - apontam uma relação inversa, números maiores para os municípios menores. A transferência per capita para os municípios com menos de 50.000 habitantes foi de $\mathrm{R} \$$ 1.899,32, já para os municípios com mais de 100.000 habitantes foi de $\mathrm{R} \$ 891,39$. Tal fato indica maior dependência dos municípios menores em relação aos recursos advindos da União. Ou seja, se essas transferências diminuírem, devido uma crise econômica, por exemplo, a prestação de serviços destes municípios pode ficar comprometidas.

Tais resultados corroboram os achados de Massardi e Abrantes (2016), que apontam que a dependência dos municípios de Minas Gerais do FPM é diretamente proporcional ao número de habitantes, até mesmo porque, este é o critério para o repasse do recurso. Esses números, diante da pandemia do COVID-19, preocupam, já que o governo federal tem sinalizado não ter condições de sustentar a ajuda financeira aos entes subnacionais por muito tempo, o que foi usado como justificativa para o fato de ser contrário ao isolamento horizontal.

Neste contexto, torna-se relevante analisar a relação entre as receitas próprias dos municípios e as transferências intergovernamentais. Os resultados apresentados sugerem que nos municípios com menos de 50.000 habitantes as receitas próprias representam apenas $6,2 \%$ em relação às transferências da União. No entanto, nos municípios com mais de 100.000 habitantes, esse percentual chega a aproximadamente $81 \%$.

Os resultados reforçam a preocupação em municípios com menos de 100 mil habitantes, que ficam restritos em estratégias de enfrentamento da doença. Seus recursos já são escassos e o discurso adotado pelo governo federal, principal financiador das transferências, não indicam a adoção de políticas mais rígidas para enfrentamento, que auxiliariam os municípios nesse percurso, tanto no cunho social quanto de financiamento público dos municípios (AQUINO et al., 2020; HENRIQUES; VASCONCELOS, 2020).

Decompondo as receitas próprias - IPTU, ITBI, ISSQN - por faixa populacional, os resultados apresentados na Tabela 2, ilustram que os municípios maiores também apresentam números melhores, no que se refere especificamente a cada imposto municipal, o que indica que municípios maiores têm maior poder arrecadatório. Destaca-se, ainda, que em todas as faixas populacionais as receitas provenientes do ISSQN foram as que tiveram maior representatividade.

Segundo Afonso e Araújo (2000), isso acontece porque os principais tributos municipais têm características urbanas e valorizam as atividades de serviços. Isso faz com que as arrecadações maiores se concentrem nas regiões de maior potencial econômico. Além do mais, a capacidade arrecadatória própria dos municípios brasileiros é diretamente proporcional ao seu tamanho (MARENCO; STROHSCHOEN; JONER, 2017). 
Tabela 2 - Receitas próprias e despesas dos munícipios brasileiros - Média em reais por faixa populacional

\begin{tabular}{ccccccc}
\hline População & IPTU & ITBI & ISSQN & Des. Correntes & Des. Pessoal & $\%^{*}$ \\
\hline Até 49.999 & 26,63 & 20,70 & 70,46 & 3092,68 & 1390,95 & 44,98 \\
50.000 a 99.999 & 71,60 & 26,55 & 118,08 & 2201,75 & 1029,87 & 46,78 \\
100.000 para cima & 128,76 & 41,70 & 226,65 & 2490,69 & 1106,56 & 44,43 \\
\hline
\end{tabular}

Nota: *Razão das despesas com pessoal em relação às despesas correntes.

Fonte: Elaborado pelos autores com base nos resultados da pesquisa.

Em relação aos resultados referentes às despesas correntes, constante na Tabela 2, os maiores valores foram encontrados nos municípios com menos de 50.000 habitantes. No que se refere às despesas com pessoal - uma das variáveis que compõem as despesas correntes observa-se que, em geral, elas representam aproximadamente $45 \%$ das despesas correntes dos municípios, independente da faixa populacional que ele se encontra. Contudo, em números absolutos, o destaque negativo vai para os municípios menores, que apresentam o maior valor per capita, que é R \$1.390,95, só para manter o quadro de pessoal.

A Tabela 3 evidencia o comportamento das receitas próprias dos municípios brasileiros por meio do IPTU, ITBI e ISSQN, entre os anos de 2006 e 2016. Os resultados corroboram os já apresentados nesse estudo e indicam que todas as variáveis em geral, apresentaram crescimento. Porém os mais expressivos se referem às despesas, que indicam aumento percentual da representatividade dos gastos com pessoal, em relação as despesas correntes.

Os percentuais referentes às despesas com pessoal podem indicar uma inépcia dos gestores públicos em administrar seus gastos correntes, o que em tempos de COVID-19 pode ter consequências negativas na capacidade dos municípios em enfrentar a pandemia, tanto do ponto de vista econômico como da saúde. Pois, se quase $60 \%$ das despesas já estão comprometidas com pessoal, o valor restante para aplicar em políticas públicas e conter crises, como a da COVID-19, fica cada vez mais restrita, ampliando os desafios encontrados pelos municípios neste período.

Tabela 3 - Receitas próprias e despesas dos munícipios brasileiros - Média anual em reais

\begin{tabular}{ccccccc}
\hline Ano & IPTU & ITBI & ISSQN & Des. Correntes & Des. Pessoal & $\%^{*}$ \\
\hline 2006 & 26,93 & 13,43 & 50,56 & 3303,74 & 1224,15 & 37,05 \\
2007 & 30,29 & 16,61 & 62,16 & 2540,22 & 1006,49 & 39,62 \\
2008 & 28,47 & 18,40 & 68,85 & 2321,00 & 1063,30 & 45,81 \\
2009 & 30,40 & 16,60 & 46,29 & 2546,20 & 1132,25 & 44,47 \\
2010 & 32,56 & 19,49 & 88,72 & 2649,27 & 1200,33 & 45,31 \\
2011 & 35,20 & 23,93 & 98,46 & 2846,69 & 1321,05 & 46,41 \\
2012 & 37,44 & 25,54 & 102,98 & 2856,86 & 1372,30 & 48,04 \\
2013 & 37,37 & 27,66 & 98,79 & 3847,61 & 1473,12 & 38,29 \\
2014 & 39,78 & 29,63 & 103,93 & 4013,87 & 1532,44 & 38,18 \\
2015 & 40,11 & 28,03 & 92,09 & 3551,21 & 2024,80 & 57,02 \\
2016 & 42,81 & 25,40 & 86,66 & 2710,03 & 1585,69 & 58,51 \\
\hline
\end{tabular}

Nota: *Razão das despesas com pessoal em relação às despesas correntes.

Fonte: Elaborado pelos autores com base nos resultados da pesquisa.

Este estudo, de maneira alguma, tem a pretensão de apontar as despesas correntes municipais como o único fator de má alocação dos recursos públicos. Porém, em razão da crise 
causada pelo COVID-19, o gestor público que conseguir otimizar suas receitas diminuindo, por exemplo, suas despesas correntes, inclusive os gastos com pessoal, pode amenizar os efeitos da pandemia. Afinal, essa otimização de recursos financeiros pode possibilitar os municípios menores prestar um melhor serviço na prevenção e no diagnóstico da doença, o que desafogaria as unidades de saúde dos grandes centros urbanos.

\section{CONSIDERAÇÕES FINAIS}

Diante do grave quadro na saúde devido a pandemia do COVID-19 e a eminente crise econômica que se anuncia, a gestão pública, com responsabilidade financeira, terá papel fundamental. Municípios, mesmo os de menor estrutura econômica, mas que administrarem melhor suas despesas, provavelmente terão condições de fornecer uma assistência mais qualificada à população. Entretanto, os resultados deste estudo apontam sentido contrário. Mesmo tendo apresentado um crescimento das receitas próprias em torno de $70 \%$ entre os anos de 2006 e 2016, as despesas correntes e com pessoal também aumentaram consideravelmente nos municípios brasileiros neste período.

Ressalta-se, porém, que as análises aqui apresentadas não têm a pretensão de afirmar com exatidão se os gestores municipais brasileiros serão capazes de administrar os recursos públicos em meio a uma pandemia mundial na saúde. Isso porque, esses gastos podem envolver variáveis que não foram analisadas neste estudo por não fazerem parte do escopo do mesmo.

Todavia, considerando os resultados, questiona-se a capacidade da gestão pública em administrar os recursos financeiros diante o grave quadro econômico que se anuncia em razão da crise do COVID-19. Os números mostraram que nos últimos anos as despesas municipais só aumentaram, principalmente, as despesas com pessoal. Gastos estes que, neste momento de união de esforços, podem comprometer a capacidade dos municípios em prover a saúde primária, dado que existe a dúvida se o governo federal será capaz de atender todas as demandas diante da possível queda na arrecadação fiscal.

Considerando ainda que a estrutura de saúde pública se torna cada vez maior conforme cresce o tamanho do município, as ações de enfrentamento da doença devem ser adotadas de forma diferente em cada situação. Se por um lado há limitação de recursos em municípios menores, o controle do contágio local se torna menos complexo de ser executado, monitorando os suspeitos de forma a não disseminar a doença, sendo uma importante estratégia de enfrentamento da doença, principalmente quando há escassez de recursos para combates mais agressivos. Contudo, tal fato não foi investigado nesse estudo, sendo uma sugestão para pesquisas futuras identificar posturas diferentes de enfrentamento à doença. 


\section{REFERÊNCIAS}

AFONSO, J. R. R.; ARAÚJO, É. A. A capacidade de gasto dos municípios brasileiros: arrecadação própria e receita disponível. In: GLEISI, N. (Ed.). . Os municípios e as eleições de 2000. São Paulo: Konrad Adenauer Stiftung, 2000. p. 35-55.

AKIN, Z.; BULUT-CEVIK, Z. B.; NEYAPTI, B. Does Fiscal Decentralization Promote Fiscal Discipline? Emerging Markets Finance and Trade, v. 52, n. 3, p. 690-705, 2016.

AQUINO, E. M. L. et al. Medidas de distanciamento social no controle da pandemia de COVID19: potenciais impactos e desafios no Brasil. Ciência \& Saúde Coletiva, v. 25, n. suppl 1, p. 2423-2446, 1 jun. 2020.

ARAÚJO, C. E. L.; GONÇALVES, G. Q.; MACHADO, J. A. Os municípios brasileiros e os gastos próprios com saúde: Algumas associações. Ciencia e Saude Coletiva, v. 22, n. 3, p. 953963, 2017.

ARRETCHE, M. Quem taxa e quem gasta: a barganha federativa na federação brasileira. Revista de Sociologia e Política, n. 24, p. 69-85, 2005.

BAHL, R.; LINN, J. Linked references are available on JSTOR for this article : Fiscal

Decentralization and Intergovernmental Transfers in Less Developed Countries. v. 24, n. 1, p. 119, 2016.

BIRD, R. M.; TARASOV, A. V. Closing the gap: Fiscal imbalances and intergovernmental transfers in developed federations. Environment and Planning C: Government and Policy, v. 22, n. 1, p. 77-102, 2004.

BREnNAN, G. B.; BUCHANAN, J. The Power to Tax: Analytical Foundations of a Fiscal Constitution. Cambridge: Cambridge University Press, 1980.

DE HOLANDA BARBOSA FILHO, F. A crise econômica de 2014/2017. Estudos Avancados, v. 31, n. 89, p. 51-60, 2017.

DO ESPÍRITO SANTO, A. C. G.; TANAKA, O. Y. Financiamento, gasto e oferta de serviços de saúde em grandes centros urbanos do estado de São Paulo (Brasil). Ciencia e Saude Coletiva, v. 16, n. 3, p. 1875-1885, 2011.

ERIKSSON, L. et al. . Multi and megavariate data analysis: basic principles and applications. $2^{\circ}$ ed. Estocolmo: Umetrics Academy, 2006.

FUNASHIMA, Y.; HIRAGA, K. Wagner's law, fiscal discipline, and intergovernmental transfer: empirical evidence at the US and German state levels. International Tax and Public Finance, v. 24, n. 4, p. 652-677, 2017.

GUEDES, K. P.; GASPARINI, C. E. Descentralização fiscal e tamanho do governo no Brasil. Economia Aplicada, v. 11, n. 2, p. 303-323, 2007.

HENRIQUES, C. M. P.; VASCONCELOS, W. Crises dentro da crise: Respostas, incertezas e desencontros no combate a pandemia da Covid-19 no Brasil. Estudos Avancados, v. 34, n. 99, p. 25-44, 1 maio 2020. 
LEITE, V. R.; LIMA, K. C.; DE VASCONCELOS, C. M. Funding, public spending and management of health resources: The current situation in a Brazilian State [Financiamento, gasto público e gestão dos recursos em saúde: O cenário de um estado brasileiro]. Ciencia e Saude Coletiva, v. 17, n. 7, p. 1849-1856, 2012.

LEROY, R. S. D. et al. Estrutura Arrecadatória e Desenvolvimento Socioeconômico dos Municípios Mineiros. Desenvolvimento em Questão, v. 15, n. 41, p. 164, 2017.

MACDOWELL, M. C.; GOMES, G. M. Descentralização política, federalismo fiscal e criação de municípios: o que é mau para o econômico nem sempre é bom para o social. Brasília: IPEA, 2000.

MARENCO, A.; STROHSCHOEN, M. T. B.; JONER, W. Capacidade estatal, burocracia e tributação nos municípios brasileiros. Revista de Sociologia e Politica, v. 25, n. 64, p. 3-21, 2017.

MASSARDI, W. D. O.; ABRANTES, L. A. Dependência dos Municípios Mineiros em relação ao Fundo de Participação dos Municípios. Gestão e Sociedade, v. 10, n. 27, p. 1416, 2016.

MASSARDI, W. DE O.; ABRANTES, L. A. CLASSIFICAÇÃO DOS MUNICÍPIOS MINEIROS EM RELAÇÃO À COMPOSIÇÃO DE SUAS RECEITAS. Gestão, Finanças e Contabilidade, v. 4, n. 1, p. 144-161, 2014.

MASSARDI, W. DE O.; ABRANTES, L. A. Esforço Fiscal, Dependência Do Fpm E Desenvolvimento Socioeconômico: Um Estudo Aplicado Aos Municípios De Minas Gerais. Revista de Gestão, v. 22, n. 3, p. 295-313, 2015.

MENDES, M. Federalismo fiscal. In: BIDERMAN, C.; ARVATE, P. R. (Eds.). . Economia do Setor Público No Brasil. Rio de Janeiro: Elsevier, 2004. p. 421-461.

MENDES, W. DE A. et al. A influência da capacidade econômica e da formação de receitas públicas no desenvolvimento humano. Revista de Administração Pública, v. 52, n. 5, p. 918 934, 2018.

MENDONÇA; JORGE, M. DIAGNÓSTICO DAS CAUSAS DA CRISE ECONÔMICA NO BRASIL E RETOMADA DO CRESCIMENTO ECONÔMICO. Revista Razão Contábil \& Finanças, v. 9, n. 2, 2019.

MUSGRAVE, R. A. The Theory of Public Finance: A Study in Public Economy. New York: McGraw-Hill, 1959.

MUSGRAVE, R. A.; MUSGRAVE, P. B. Public finance in theory and practice. $5^{\circ}$ ed. New York: McGRAW-Hill, 1989.

OATES, W. E. An Essay on Fiscal Federalism. Journal of Economic Literature, v. 37, n. 3, p. 1120-1149, 1999.

OATES, W. E. An essay on fiscal federalism. Fiscal Federalism and European Economic Integration, v. 37, n. 3, p. 13-47, 2003.

PRUD'HOMME, R. The dangers of decentralization. The world bank research observer, v. 10, n. 2, p. 201-220, 1995. 
REZENDE, F. DA C. Fatores políticos e institucionais nas teorias contemporâneas sobre a expansão dos gastos públicos. Revista de Economia Política, v. 26, n. 2, p. 274-289, 2006.

RODDEN, J. The Dilemma of Fiscal Federalism: Grants and Fiscal Performance around the World. American Journal of Political Science, v. 46, n. 3, p. 670, 2002.

SANTOS, C. M. L. DA S. A. DOS. Estatística Descritiva - Manual de Auto-aprendizagem. $3^{\text {a }}$ ed. Lisboa: Edições Sílabo, 2018.

SERRA, J.; AFONSO, J. R. R. Federalismo Fiscal à Brasileira: Algumas Reflexões. Revista Do BNDES, v. 6, n. 12, p. 3-30, 1999.

SICSU, J. Brazil: It's a depression, it was not a recession. Revista de Economia

Contemporanea, v. 23, n. 1, 2019.

SILVA, F. A. G. H. DA; QUINTELA, M. C. DE A.; VIEIRA, N. D. S. Perfil Orçamentário de Pequenos Municípios: O Caso do Município de Ladainha - MG. Revista de Administração, Sociedade e Inovação, v. 4, n. 2, p. 160-182, 11 jul. 2018.

SILVA, M. Teoria do federalismo fiscal : notas sobre as contribuições de Oates, Musgrave, Shah e Ter-Minassian. Nova Economia, v. 15, n. 1, p. 117-137, 2005.

SOUZA, C. Federalismo, desenho contitucional e instituições federativas no Brasil pós-1988.

Revista de Sociologia e Política, n. 24, p. 105-121, jun. 2005.

SUZART, A. DA S.; ZUCCOLOTTO, R.; ROCHA, D. G. DA. Federalismo Fiscal E As Transferências Intergovernamentais: Um Estudo Exploratório Com Os Municípios Brasileiros. Advances in Scientific and Applied Accounting, v. 11, n. 1, p. 127-145, 2018.

VARELA, P. S.; FARINA, M. C. Relação Entre Gastos Com Saúde,Índice De Esforços Da Atenção Básica Em Saúde E Tipologia Da Estrutura Do Sistema De Saúde Dos Municípios Do Estado De São Paulo. RAM. Revista de Administração Mackenzie, v. 8, n. 3, p. 153-172, 2007.

VARGAS, N. C. A descentralização e as teorias do Federalismo Fiscal. Ensaios FEE, v. 32, n. 1, p. 51-76, 2011.

VIEIRA, M. A. et al. Implicações Do Esforço De Arrecadação No Desempenho Socioeconômico Dos Municípios De Minas Gerais. Gestão \& Regionalidade, v. 33, n. 99, 2017.

WEINGAST, B. R. Second generation fiscal federalism: The implications of fiscal incentives. Journal of Urban Economics, v. 65, n. 3, p. 279-293, 2009. 